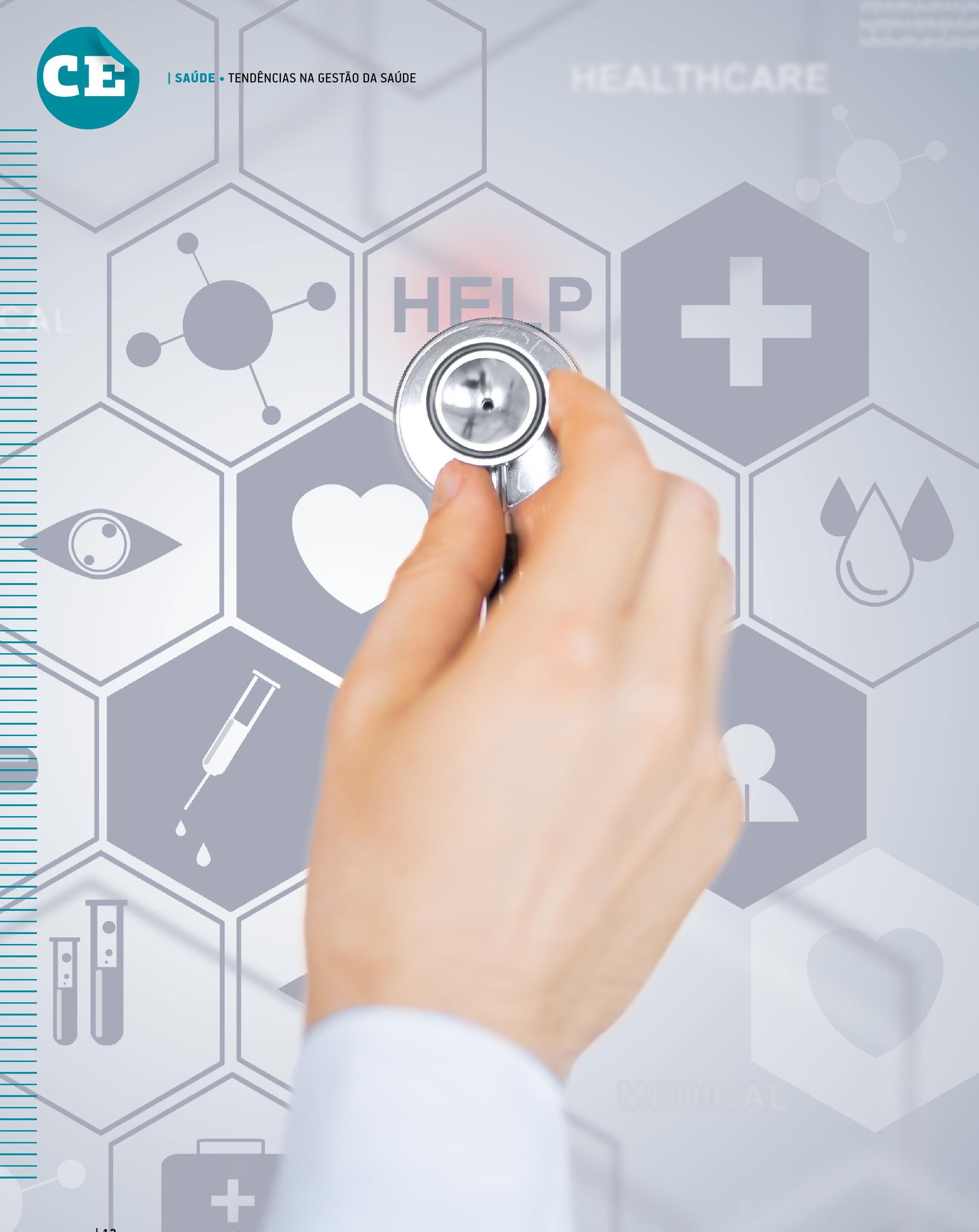




\section{TENDÊNCIAS NA GESTÃO DA SAÚDE}

\section{Como pagar a conta do sistema e como garantir o acesso}

de todos aos novos tratamentos são as duas questões
deste século. A resposta está nas possíveis melhorias
com a revolução tecnológica.

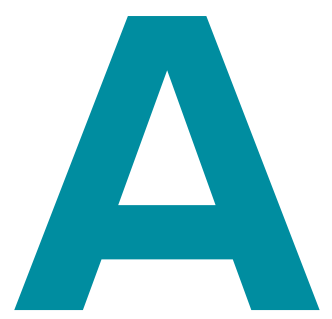

s tendências para a saúde identificadas nos últimos 50 anos se tornaram características do início do século XXI. $\mathrm{O}$ número de nascimentos diminuiu, as mortes por causas evitáveis (ou doenças preveníveis por saneamento básico ou vacinas) reduziram e a proporção da população que atingirá os 60 anos aumentou. No Brasil, considerado um país jovem até o ano 2000, já se estima que a população idosa triplicará entre 2010 e 2050. Será uma mudança muito rápida. Nos países desenvolvidos, esse fenômeno ocorreu lentamente. Enquanto as decisões para construir um caminho rumo ao envelhecimento saudável e ativo continuarem sendo adiadas, os sistemas de saúde vão se manter despreparados para a nova realidade.

Além do envelhecimento populacional, outra transformação vem ocorrendo no padrão do processo de adoecer e morrer. Cerca de $80 \%$ das mortes no Brasil são causadas por doenças cardiovasculares e cânceres, além da violência. Hoje, o modelo oferecido tanto no setor público como no privado é baseado em intervenções individuais. No entanto, a assistência a essas doenças exige um modelo de atenção contínuo e integral. No caso da violência, é imprescindível uma proposta mais complexa e intersetorial.

O cenário fecha-se com a explosão de oferta de tecnologias para tratar doenças. Surgem novas drogas, técnicas e equipamentos cada vez mais caros, particularmente quando se pensa em sistemas universais de atenção à saúde.

Os custos têm sido vistos como uma das poucas certezas do setor: continuarão crescendo. Países como os Estados Unidos gastam cerca de $18 \%$ de seu produto interno bruto (PIB) em saúde, com resultados discutíveis em comparação aos países europeus, que despendem, em média, de 10 a $12 \%$. Esses percentuais tendem a aumentar por causa das 


\section{As mudanças na gestão da saúde, particularmente na área de Tecnologia da Informação, devem promover um ganho importante da eficiência.}

novas tecnologias e pelo crescimento da população mais velha. Pessoas com mais de 60 anos consomem seis vezes mais internações que adultos na faixa dos 40 anos.

Neste novo século, a medicina vem fazendo a diferença: é possível viver mais e melhor. Porém, duas questões se colocam: como pagar a conta desse desenvolvimento e como garantir seu acesso a todos, evitando, assim, a piora da exclusão social e da desigualdade.

\section{TENDÊNCIAS}

\section{Em gestão com Tecnologia da Informação}

Parte da resposta à questão de como viabilizar um sistema universal de saúde está na gestão. Falta eficiência nos sistemas de saúde público e privado no Brasil, e as mudanças em administração nesse segmento, particularmente na área de Tecnologia da Informação, permitem um ganho importante nesse aspecto.

Destacam-se os seguintes sistemas para cuidado dos pacientes:

- Prontuário Eletrônico do Paciente (PEP): o PEP integra as ações dos serviços de saúde, os gastos e os registros dos pacientes. Permite, por exemplo, estudar o consumo de exames e medicamentos para o desenvolvimento de melhores práticas;

- Internet das Coisas (Internet of Things - IoT): a conexão entre todos os aparelhos utilizados no dia a dia também envolve a área de saúde. Aparelhos podem medir passivamente sinais vitais dos pacientes e enviar informações instantaneamente a qualquer local. A expectativa é que sua adoção massiva reduza em até $30 \%$ o tempo para checar e interpretar dados vitais;

- Wearables ou healthwears: são os equipamentos de IoT que registram dados para monitorar doentes crônicos a distância e controlar atividades da vida diária e/ou exercícios físicos. Podem registrar os dados colhidos em conexão com o PEP;
- Healthons: diferentemente dos healthwears, são mecanismos implantáveis no corpo. Monitoram, diagnosticam e tratam imediatamente o paciente. Desde os anos 1970 existem exemplos desses dispositivos, como o marca-passo cardíaco. Mais recentemente surgiram novos healthons, como: controladores de glicemia, que administram insulina segundo a necessidade; bombas implantáveis, que permitem o controle da dor por meio da liberação de drogas analgésicas continuamente ou por ação do paciente; drogas implantáveis para controlar o fluxo hormonal, que agem como anticoncepcionais; e outras drogas de liberação lenta, que substituem a necessidade da ingestão deliberada e contribuem para a adesão a tratamentos longos.

Também ganha importância a Tecnologia da Informação aplicada na organização das redes de saúde, de forma a evitar duplicações de procedimentos, melhorar o acompanhamento do cidadão em seu percurso nas redes, garantir a utilização de protocolos de atenção e ajudar em sua integralidade, entre outros benefícios. Com o uso de tecnologias, é possível construir fluxos de pacientes entre os diferentes serviços que compõem a rede de saúde local, tornando mais dinâmica e transparente a regulação da oferta de atos médicos, como consultas, cirurgias e exames. Isso já ocorre em escala reduzida no caso das filas de transplantes, que, no Brasil, são únicas e acessíveis por sistemas eletrônicos.

\section{Em sistemas de remuneração}

Outro campo que deve mudar é o de pagamento dos serviços de saúde. Hoje, o modelo predominante é o de remuneração por serviço prestado (fee for service), que estimula a realização de procedimentos nem sempre necessários. Muito se tem discutido sobre mudar esse parâmetro e adotar o pagamento por performance ou em função do valor agregado ao cliente. A dificuldade tem sido desenvolver ferramentas que consigam captar esses indicadores. Com a implantação do PEP e o uso mais intensivo da Tecnologia da Informação, será possível criar essas novas modalidades de pagamento.

\section{Em avaliação da}

\section{incorporação de tecnologias}

Indicadores originados da economia da saúde prometem melhorar a avaliação do impacto da adoção de novos processos, medicamentos ou equipamentos. Estes indicadores são: Quality Adjusted Life Years (QALY, em português: Anos de Vida Ajustados por Qualidade), Healthy Years Equivalent (HYE, em português: Equivalente em 


\section{GASTOS EM SAÚDE COMO \% DO PIB}

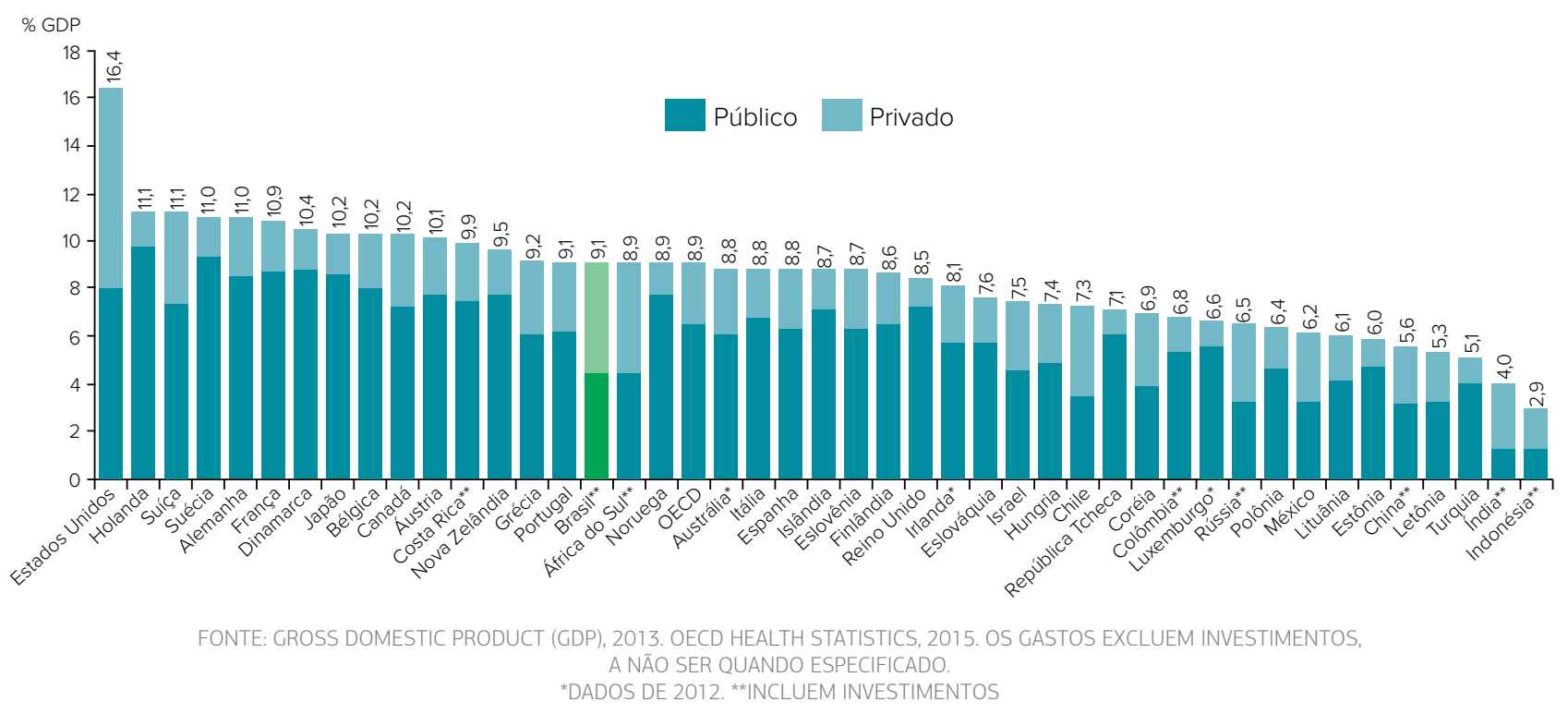

Anos Saudáveis) e Disability Adjusted Life Years (DALY, em português: Anos de Vida Ajustados por Incapacidade). Eles conseguem traduzir dados em termos de impacto na qualidade de vida das pessoas, o que somente era medido em termos econômicos.

\section{Em autocuidado}

Se essas transformações já não são pequenas, o impacto da revolução tecnológica será ainda maior para empoderar o próprio cidadão, paciente ou não. $\mathrm{O}$ aumento do acesso à informação diminui a assimetria em relação aos prestadores de serviço e amplia a possibilidade de os pacientes participarem ativamente de seu próprio cuidado.

Até pouco tempo, a medicina tinha como preocupação fundamental a cura. Com os novos conhecimentos nos campos da genética (o que somos) e da epigenética (o que poderemos ser), o objetivo passou a ser promover a saúde, ou seja, evitar ou atrasar o início da doença. Os pacientes passam a tomar decisões, em conjunto com especialistas, que interferem no que poderá vir a ser realidade, como ocorreu com a atriz Angelina Jolie, que se submeteu a uma mastectomia baseada na informação genética de que sua probabilidade de desenvolver câncer de mama era alta.

No campo da epigenética, estudam-se as relações do genoma com o ambiente e com os hábitos de vida. Complexas

reações podem ligar ou suprimir a ação de certos genes e desencadear (ou proteger contra) enfermidades. Alimentação saudável, prática de exercícios e relação com o meio ambiente são alguns hábitos que podem fazer cada vez mais diferença.

\section{No sistema brasileiro}

Mais recursos financeiros não serão suficientes para resolver os problemas da saúde no Brasil. O percentual de gastos na área em relação ao PIB do país é semelhante ao de nações mais desenvolvidas (cerca de 10\%), embora a proporção entre recursos públicos e privados seja diferente. A parcela 


\section{GASTOS EM SAÚDE PER CAPITA (US\$) PELA PARIDADE DO PODER DE COMPRA (PPP)}

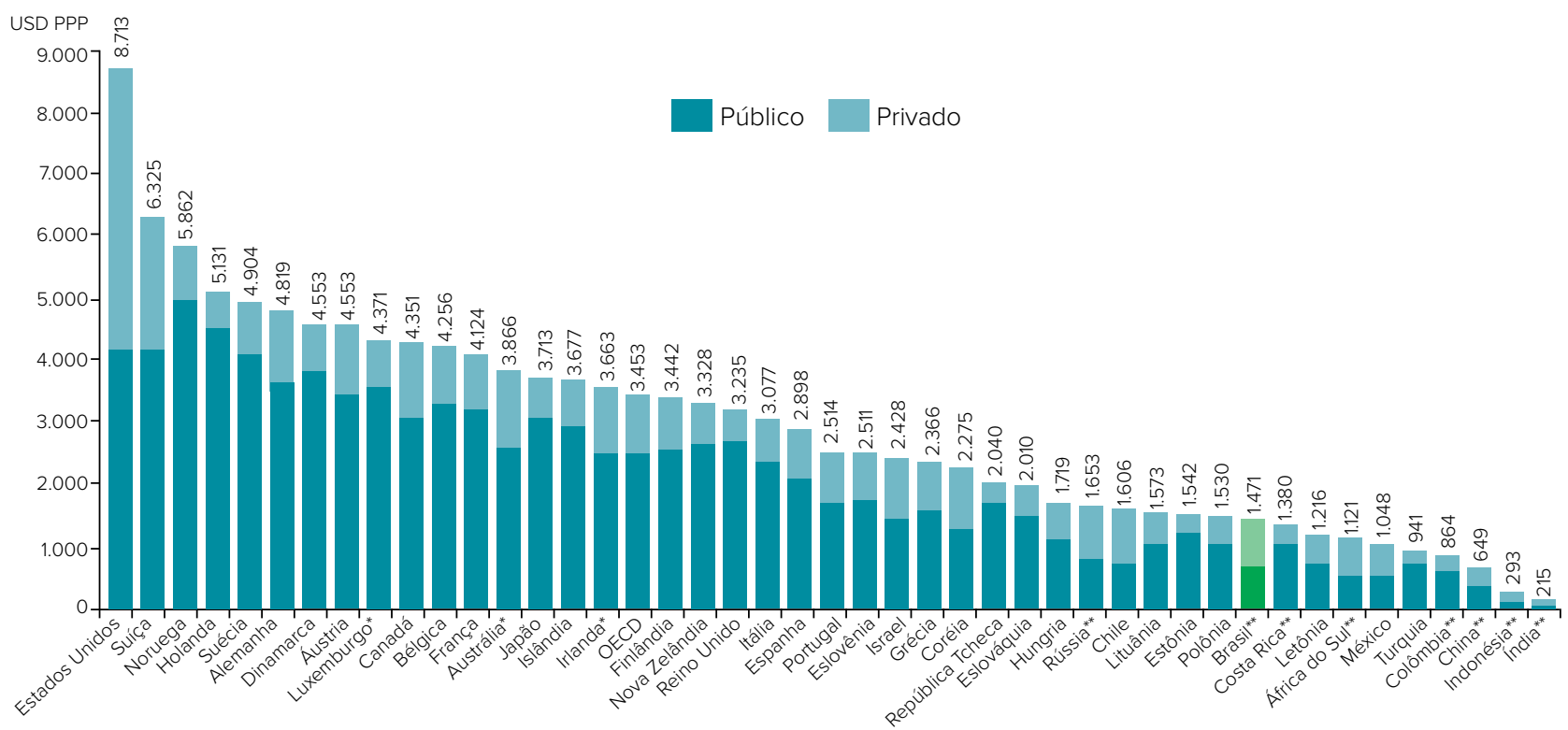

FONTE: OECD HEALTH STATISTICS 2015 (DADOS DE 2013). OS GASTOS EXCLUEM INVESTIMENTOS, A NÃO SER QUANDO ESPECIFICADO. *DADOS DE 2012. **INCLUEM INVESTIMENTOS

dos gastos privados, do qual fazem parte o orçamento das famílias e as despesas das empresas que fornecem planos de saúde privados como benefício a seus empregados, corresponde a $60 \%$ do total. Nos países da Organização para a Cooperação e o Desenvolvimento Econômico (OECD), os gastos como porcentagem do PIB situam-se entre $10 \mathrm{e}$ $14 \%$, sendo $70 \%$ públicos e oriundos de cargas tributárias relacionadas à renda, e não ao consumo. Ou seja, induzem mais equidade.

Quando calculado per capita, o percentual do PIB representa cerca de um terço do que se verifica em países europeus. Portanto, o cobertor é curto, ainda mais considerando que os gastos com saúde diminuem em momentos de crise econômica.

Provavelmente, nos próximos anos, será criado um modelo mais harmonioso de integração do Sistema Único de Saúde (SUS) com os subsistemas privados. Em 2017, ainda se verificam diversas sobreposições: 1) embora cerca de $25 \%$ da população tenha acesso a cuidados privados, todos os brasileiros têm direito ao SUS (a todos os seus serviços, desde as vigilâncias à saúde até assistência de alta complexidade); 2) dos $25 \%$ da população com acesso a cuidados privados, $80 \%$ recebe o benefício do empregador, 19\% paga planos de saúde individuais e $1 \%$ compra serviços diretamente (o chamado out of pocket). $\mathrm{O}$ mesmo serviço, para a mesma pessoa, pode ser consumido três vezes, gerando retrabalho e, consequentemente, ineficiência e desperdício.

Hoje, o que se discute são meias soluções: diminuir os serviços do SUS e/ou criar planos de saúde deficientes e mais baratos. Ambos os casos representam uma oferta pobre para pobres. Em países desenvolvidos, existem verdadeiros sistemas universais de atenção à saúde. Planos de saúde privados prometem sofisticação e ausência de filas, mas, na base, não existe diferença na oferta de soluções aos problemas de saúde. Sistemas universais são fundamentais para garantir o status civilizatório que alcançaram e que deve ser solidariamente financiado.

\section{PARA SABER MAIS: \\ Gonzalo Vecina Neto e Ana Maria Malik. Gestão em saúde, 2016.}

GONZALO VECINA NETO > Professor do Mestrado Profissional em Gestão para a Competitividade (MPGC) da FGV EAESP e docente da Faculdade de Saúde Pública (FSP) da USP > gvecina@uol.com.br

ANA MARIA MALIK > Professora da FGV EAESP > ana.malik@fgv.br 